\title{
Evaluation of Two Sorbents for the Sorption-Enhanced Methanation in a Dual Fluidized Bed System
}

\author{
A. Coppola ${ }^{1}$, F. Massa ${ }^{1}$, P. Salatino ${ }^{1,2}$, F. Scala ${ }^{1,2^{*}}$ \\ 1. Dipartimento di Ingegneria Chimica, dei Materiali e della Produzione Industriale, Università degli Studi di \\ Napoli Federico II, Piazzale V. Tecchio 80, 80125 Napoli, Italy \\ 2. Istituto di Ricerche sulla Combustione, CNR, Piazzale V. Tecchio 80, 80125 Napoli, Italy \\ *corresponding author, fabrizio.scala@unina.it
}

\begin{abstract}
The unceasing concern for climate change, closely related to the exploitation of fossil fuels, pushes the scientific community to develop new technologies for $\mathrm{CO}_{2}$ capture and utilization (CCU). Moreover, the growth and diffusion of solar energy requires new energy storage systems that put solar fuels at the forefront. Methane seems to be a suitable energy vector, which could both store solar energy and exploit fossil fuel derived $\mathrm{CO}_{2}$. Moreover, methane has the main advantage of an already existing distribution and storage infrastructure.

The methanation reaction from hydrogen and carbon dioxide (or monoxide) is generally carried out in staged adiabatic catalytic fixed beds operated at high pressure in order to overcome thermodynamic limitations. A recently proposed alternative pathway is the sorptionenhanced methanation concept, which is based on the employment of a sorbent able to capture in situ the $\mathrm{H}_{2} \mathrm{O}$ produced during reaction, to shift equilibrium towards the formation of $\mathrm{CH}_{4}$.

In this work a $\mathrm{CaO}$, derived from natural limestone, and a commercial 3A Zeolite were tested as sorbent materials for $\mathrm{H}_{2} \mathrm{O}$ capture in a new configuration for the sorption-enhanced methanation based on the concept of chemical looping in dual interconnected fluidized bed systems. The experimental campaign was aimed at studying the sorbent performance in terms of hydration and dehydration at different operating conditions relevant for catalytic methanation. The results showed that $\mathrm{CaO}$ has a good capacity to capture and release steam in the temperature range of interest. Unfortunately, even at the lowest temperatures tested, the sorbent is affected by the presence of $\mathrm{CO}_{2}$, which worsens its performance in terms of $\mathrm{H}_{2} \mathrm{O}$ capture capacity. The zeolite has a more stable behavior than $\mathrm{CaO}$ under all investigated conditions. Comparing the performance of the two materials, the zeolite on average has better capture capacity $(0.017-0.049 \mathrm{~g} / \mathrm{g})$ than $\mathrm{CaO}(0.006-0.025 \mathrm{~g} / \mathrm{g})$ and it is not affected by deactivation during the cycles.
\end{abstract}

\section{Introduction:}

Methane is an important energy carrier for many sectors, which features a welldeveloped distribution and storage infrastructure in many countries, and its massive utilization in the automotive, household and industrial sectors.
Nowadays, natural gas is the main source of methane, however the increasing dispute on global warming related to the exploitation of fossil fuels has moved the interest to alternative and renewable technologies for methane production, such as catalytic and biological methanation processes [1-3]. 
Specifically, catalytic methanation [4], via $\mathrm{CO}$ (Eq.1) or via $\mathrm{CO}_{2}$ (Eq.2), has several features that makes it very interesting if combined with the concepts of solar fuels, chemical storage and $\mathrm{CO}_{2}$ utilization. Indeed, methane could act as chemical storage carrier of solar energy [2] initially used to convert water into hydrogen by electrolysis [5]. Moreover, $\mathrm{CO}_{2}$ methanation could be considered as a process for $\mathrm{CO}_{2}$ utilization in the framework of Carbon Capture and Utilization (CCU) technologies [6-10]. On the other hand, the production of methane from $\mathrm{CO}$ could represent the final step after coal or biomass gasification into syngas [11-13].

$$
\begin{aligned}
& 3 \mathrm{H}_{2}+\mathrm{CO} \rightleftharpoons \mathrm{CH}_{4}+\mathrm{H}_{2} \mathrm{O} \\
& 4 \mathrm{H}_{2}+\mathrm{CO}_{2} \rightleftharpoons \mathrm{CH}_{4}+2 \mathrm{H}_{2} \mathrm{O}
\end{aligned}
$$

The typical catalysts able to promote methanation are based on different metals such as $\mathrm{Ru}, \mathrm{Ni}, \mathrm{Co}, \mathrm{Fe}$, and $\mathrm{Mo}$ [14], though Ni-based catalysts are considered to provide the best compromise among activity, selectivity and low price [15-17]. Commercial methanators consist of fixed beds, typically operated at high pressure to obtain high methane yields, and arranged in series in order to carry out intermediate cooling steps and recycles to manage the temperature of the process (due to the high exothermicity of the reaction) $[1,20]$. In particular, the temperature management represents the main issue for the process because it may lead to the deactivation of the catalyst [18]. In addition, the high temperature can promote carbon deposition on the catalyst surface due to the Boudouard reaction [19]. In the last years, many research groups have proposed new solutions, based on new reactor designs (fluidized bed reactors, three-phase reactors), to improve the current methanation process with the goal to have a better temperature control [2].
Recently, Borgschulte et al. [21] and Walspurger et al. [22] investigated the possibility to enhance the methane production by the application of the concept of Sorption-Enhanced Methanation (SEM), where the steam, produced by the methanation reaction, is continuously removed from the reaction environment by means of a suitable regenerable sorbent material, e.g. a zeolite. These studies demonstrated in a lab scale fixed bed apparatus that the SEM process has the potential for high-grade methane production at low pressure using commercial materials, with the consequence of a relevant energy saving for the entire process.

Based on these promising outcomes, in this work an innovative configuration for the SEM process is proposed. This configuration takes advantage of the chemical looping concept where in one reactor (methanator) catalytic methanation occurs simultaneously with the hydration of a suitable sorbent, so as to drive the equilibrium towards product formation, while the regeneration of the sorbent takes place in another reactor (dehydrator). The two reactors are connected each other in a dual-interconnected fluidized beds configuration as shown in Fig. 1. This scheme has the advantage of a steady operation of the plant, thus avoiding the unsteady cyclic operation necessary for sorbent regeneration in fixed bed reactors. In addition, the use of fluidized bed reactors appears to be suitable to achieve good temperature control for highly exothermic reactions like methanation.

In this work, two potential sorbents were tested for their steam capture potential in a lab-scale dual bed fluidized bed apparatus: $\mathrm{CaO}$, derived from natural limestone, and a commercial 3A-zeolite. The main aim was to evaluate the sorbent performance in terms of hydration and dehydration cycles at different operating conditions relevant for catalytic methanation. 


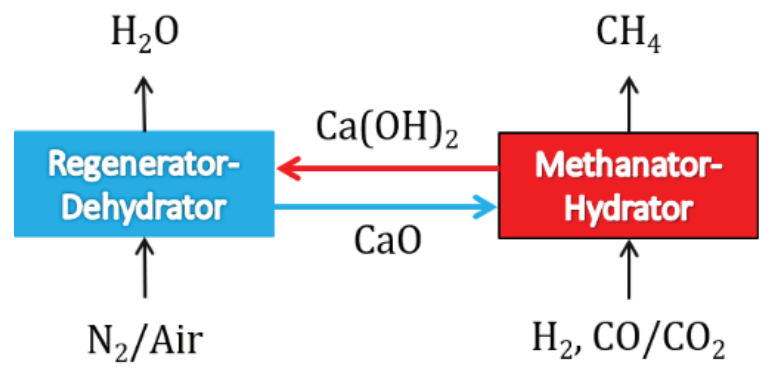

Fig.1: Scheme of the Chemical Looping SorptionEnhanced Methanation concept

\section{Experimental:}

Two materials were tested as sorbents for SEM: a $\mathrm{CaO}$ and a zeolite. $\mathrm{CaO}$ was obtained by calcination of an Italian limestone named Massicci: the material was prepared in a lab-scale fluidized bed at $850^{\circ} \mathrm{C}$ with air for $20 \mathrm{~min}$. The zeolite was a spherical commercial $3 \mathrm{~A}$-zeolite.

The experimental apparatus used for the tests, called Twin Beds (Fig.2), consists of two identical lab-scale bubbling fluidized beds connected by a rapid solid transfer line. This system is an ad hoc device used to study looping processes. The two reactors have an inner diameter of $40 \mathrm{~mm}$, and are divided in two sections: a wind box also used as gas preheater; a fluidized bed, separated from the wind box by a perforated plate gas distributor. Both reactors operate separately in batch mode but they are connected each other by a duct (ID $10 \mathrm{~mm}$ ), partially immersed in both beds, used for fast pneumatic conveying of the sorbent between the two reactors. Transfer of sorbent is accomplished by using a valve system arranged along the duct and at the outlet of the reactors. The solid is injected into the system by a steel hopper connected sideways to the reactor. The apparatus is also equipped with an additional vertical duct, located in the middle between the two beds and connected with the transport duct by means of a 3-way valve; at the bottom of this duct a removable stainless-steel container is placed. The aim of this duct is to allow a fast discharge of the reactors and to collect the whole bed material into the container at the end of each test. A thorough description of the operating principle of the TB system is reported elsewhere [23].

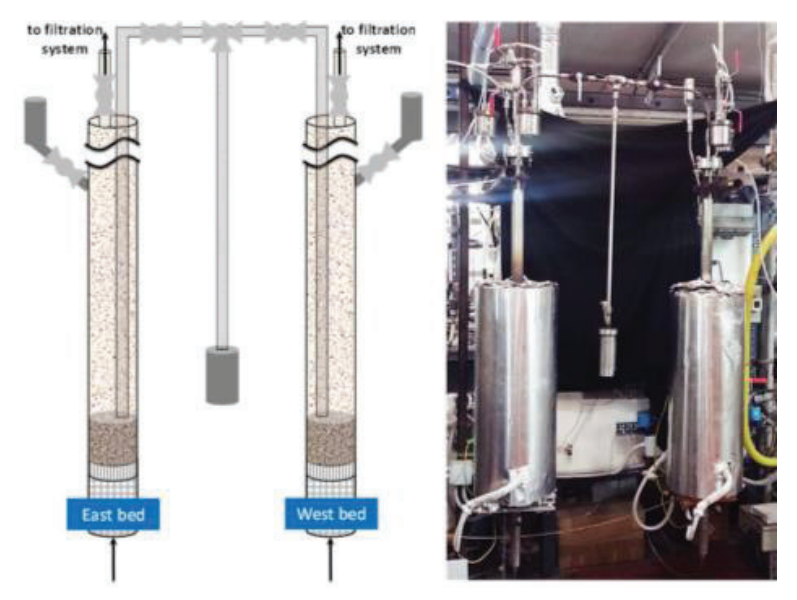

Fig.2: Twin Beds Apparatus

The two reactors were employed as hydrator and dehydrator respectively. The experimental campaign was aimed at evaluating the suitability of the sorbents to capture and release water at different temperatures and reaction environments relevant for methanation. A steam generation system, that permits to produce steam at $200^{\circ} \mathrm{C}$, was used to generate the gaseous flow for the hydration step.

The main operating conditions were: hydration with $10 \%$ steam (balance air) and dehydration in air. A sensitivity analysis on temperature was carried out varying both the hydration and the dehydration temperature (one at a time, while keeping the other fixed). The temperature range investigated for hydration was $200-300^{\circ} \mathrm{C}$, while that for dehydration was $350-450^{\circ} \mathrm{C}$. As an example, the acronym M-H25A-D35N is a typical name used to identify one test where the first letter specifies the sorbent ( $M=$ Massicci lime; $Z=$ zeolite), H25A indicates the hydration step at $250^{\circ} \mathrm{C}$ in air, while D35A indicates the dehydration step at $350^{\circ} \mathrm{C}$ in air. All the conditions investigated are summarized in Table 1. 


\begin{tabular}{|c|c|c|c|c|}
\hline & \multirow{2}{*}{ Temperature } & \multicolumn{3}{|c|}{ Fluidizing gas } \\
\hline & & $\mathrm{H}_{2} \mathrm{O}$ & $\mathrm{CO}_{2}$ & Balance \\
\hline $\mathrm{X}^{*}-\mathrm{H} 20 \mathrm{~A}-\mathrm{D} 35 \mathrm{~A}$ & $250 / 350\left({ }^{\circ} \mathrm{C}\right)^{* *}$ & \multirow{7}{*}{$10 / 0$ (\%vol) } & \multirow{7}{*}{ 400/400 (ppm) } & \multirow{7}{*}{ Air/Air } \\
\hline X-H25A-D35A & $250 / 350\left({ }^{\circ} \mathrm{C}\right)$ & & & \\
\hline X-H25A-D40A & $250 / 400\left({ }^{\circ} \mathrm{C}\right)$ & & & \\
\hline $\mathrm{X}-\mathrm{H} 25 \mathrm{~A}-\mathrm{D} 45 \mathrm{~A}$ & $250 / 450\left({ }^{\circ} \mathrm{C}\right)$ & & & \\
\hline X-H30A-D35A & $300 / 350\left({ }^{\circ} \mathrm{C}\right)$ & & & \\
\hline X-H30A-D40A & $300 / 400\left({ }^{\circ} \mathrm{C}\right)$ & & & \\
\hline X-H30A-D45A & $300 / 450\left({ }^{\circ} \mathrm{C}\right)$ & & & \\
\hline
\end{tabular}

Tab.1: Main operating conditions

The progress of hydration and dehydration reactions was followed during the tests by measuring the steam concentration at the outlet of the reactors by means of a calibrated humidity sensor. Each test consisted of 10 complete cycles, with a fluidization velocity fixed at $0.5 \mathrm{~m} / \mathrm{s}$, while the time of each hydration or dehydration step was fixed at $10 \mathrm{~min}$. The $\mathrm{H}_{2} \mathrm{O}$ capture capacity of the material, during each hydration stage, was evaluated by timeintegration of the outlet $\mathrm{H}_{2} \mathrm{O}$ profile.

\section{Results and discussion}

Steam capture tests for Massicci $\mathrm{CaO}$.

Figure 3 reports the steam capture capacity of the sorbent with the number of cycles, expressed as grams of captured $\mathrm{H}_{2} \mathrm{O}$ per gram of initial $\mathrm{CaO}$, for all the conditions investigated. In general, the performance of $\mathrm{CaO}$ tends to decay with the number of cycles, and to reach an asymptotic value after the $6^{\text {th }}-7^{\text {th }}$ cycle. Moreover, the $2^{\text {nd }}$ cycle typically presents a higher value of steam capture than the $1^{\text {st }}$ cycle. This trend is most likely due to the different value of molar density between calcium hydroxide and calcium oxide (which is lower for the first one), with a consequent swelling of the particle during the $1^{\text {st }}$ hydration, which entails an alteration of the sorbent microstructure with the formation of a highly porous $\mathrm{CaO}$ after the 1 st dehydration step [24].

The decay after the $2^{\text {nd }}$ cycle is the consequence of two effects: the first one is the occurrence of attrition phenomena which imply the removal of sorbent material leaving as fines from the reactor with the outlet gas; the second effect is caused the irreversible carbonation of the $\mathrm{CaO}$ with the $\mathrm{CO}_{2}$ contained in air, consuming active $\mathrm{CaO}$ from the sorbent.

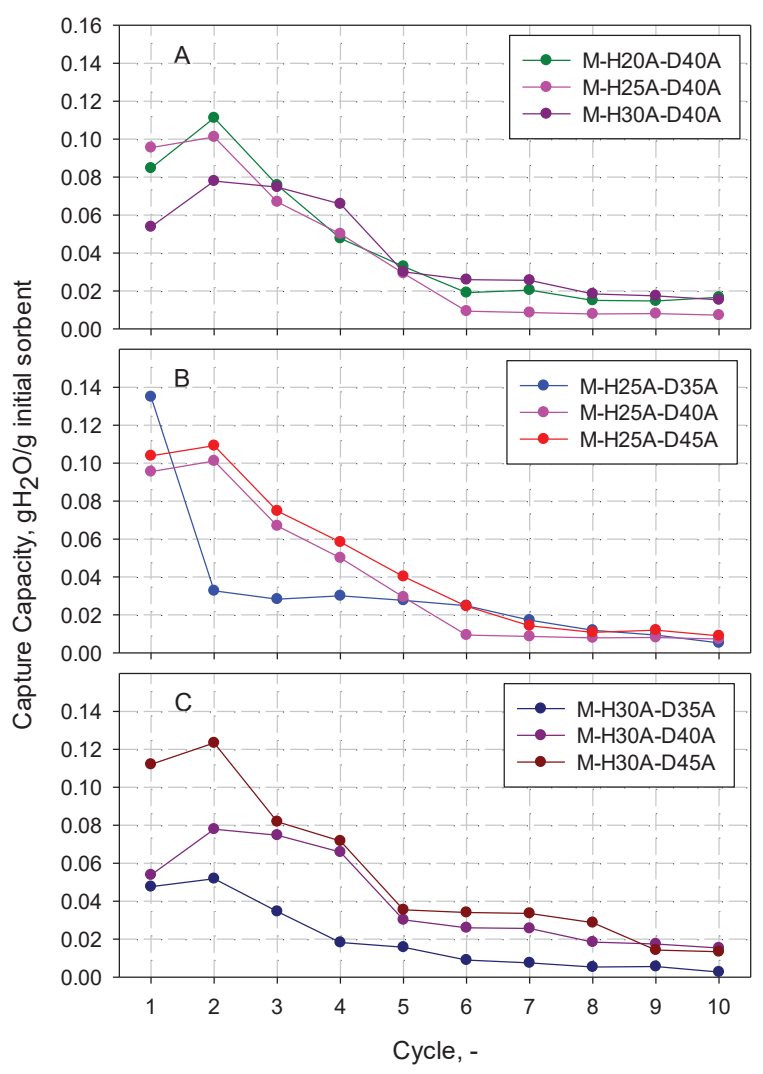

Fig.3: $\mathrm{H}_{2} \mathrm{O}$ capture capacity of the sorbent with the number of cycles for Massicci $\mathrm{CaO}$

In Fig. 3-A the results of the tests $\mathrm{M}$ H20A-D40A, M-H25A-D40A and MH30A-D40A are reported, at a fixed dehydration temperature of $400^{\circ} \mathrm{C}$, and for three different hydration temperatures $\left(200,250\right.$ and $\left.300^{\circ} \mathrm{C}\right)$. The steam capture capacity decreases with the hydration temperature and this difference is evident during the first cycles and tends to vanish with the increase of the number of cycles. This behavior is related to the higher hydration (and carbonation) kinetics which determines the formation of a plugging layer of $\mathrm{Ca}(\mathrm{OH})_{2}$ (and $\mathrm{CaCO}_{3}$ ) which hinders the diffusion of steam in the particle core. The asymptotic capacity values are similar among the samples and range around $0.008-0.019 \mathrm{~g} / \mathrm{g}$. 
The effect of the dehydration temperature was investigated setting two different hydration temperatures of 250 and $300^{\circ} \mathrm{C}$ and varying the dehydration temperature $\left(350,400\right.$ and $\left.450^{\circ} \mathrm{C}\right)$. The results are shown in Figs. 3-B and 3-C. In general, the increase of the regeneration (dehydration) temperature improves the steam capture capacity but these differences are only significant during the first cycles and tend to disappear with the increase of the cycle number. Probably, this behavior may be explained by the fact that faster dehydration (at higher temperatures) determines overpressures inside particle that induce a more severe breakage of the particles with the formation of new surface for the subsequent hydration step [25]. However, these effects appear to be more relevant at the highest hydration temperature, in particular during the first cycles (compare Figs. 3-B and 3-C).

\section{Steam capture tests for 3 A Zeolite.}

Figure 4 (A-C) reports the steam capture capacity of the sorbent with the number of cycles, expressed as grams of captured $\mathrm{H}_{2} \mathrm{O}$ per gram of initial zeolite, for all the condition investigated. In general, the behavior of the zeolite is quite stable along the cycles with a slight increase of the capture capacity during the first cycles that indicates a sort of feeble activation.

Similar to $\mathrm{CaO}$, the influence of the hydration temperature was studied fixing the dehydration temperature at $400^{\circ} \mathrm{C}$ and varying the hydration temperature at 200 , 250 and $300^{\circ} \mathrm{C}$ (Fig. 4-A). It is possible to note a slight negative influence of hydration temperature, in particular for the test Z-H30A-D40A, which shows an average capture value of about $0.022 \mathrm{~g} / \mathrm{g}$, compared to 0.044 and $0.049 \mathrm{~g} / \mathrm{g}$ for Z-H20A-D400A and Z-H25A-D40A, respectively. This effect is due to the worsening of physical absorption of $\mathrm{H}_{2} \mathrm{O}$ on the sorbent surface at higher temperatures.

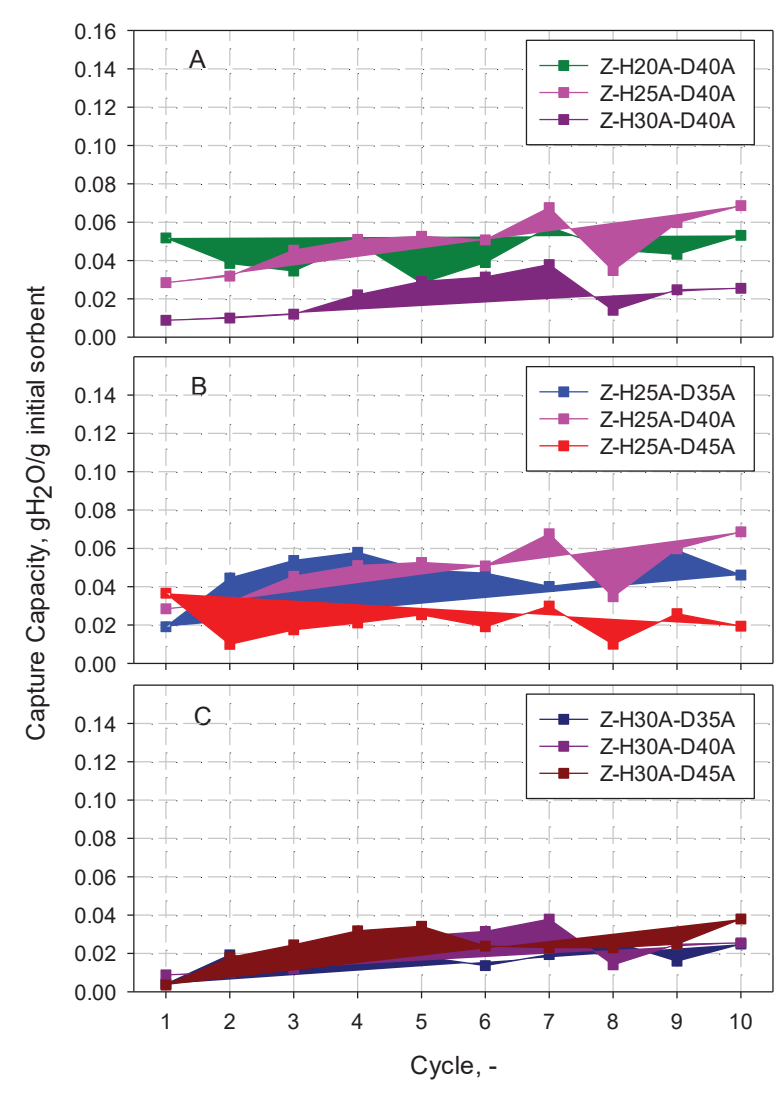

Fig.4: $\mathrm{H}_{2} \mathrm{O}$ capture capacity of the sorbent with the number of cycles for $3 \mathrm{~A}$ Zeolite

In Figs. 4-B and 4-C the effect of the dehydration temperature was examined (350, 400 and $450^{\circ} \mathrm{C}$ ) for two different hydration temperatures $\left(250\right.$ and $\left.300^{\circ} \mathrm{C}\right)$. In particular, when the hydration temperature was set to $250^{\circ} \mathrm{C}$ (Fig. 4-B), the increase of the dehydration temperature seems to have a limited effect until $400^{\circ} \mathrm{C}$ (average values of 0.046 and $0.049 \mathrm{~g} / \mathrm{g}$ for Z-H25A-D35A and Z-H25A-D40A respectively), while the capture capacity significantly decreases at $450^{\circ} \mathrm{C}$ (average value of $0.22 \mathrm{~g} / \mathrm{g}$ for Z-H25A-D45A). This behavior is most likely caused by the chemical degradation of the sorbent at $450^{\circ} \mathrm{C}$, probably related to the release of water contained in the zeolite structure.

When the hydration temperature was $300^{\circ} \mathrm{C}$, the steam capture capacity records a relevant decay for all investigated dehydration temperatures. As matter of fact, the average capacity values were $0.017,0.022$ and $0.024 \mathrm{~g} / \mathrm{g}$ for the tests Z- 
H30A-D35A, H30A-D40A and H30A-D45A, respectively. Probably, the hydration temperature limits from a thermodynamic point of view the physisorption of water as detected for the tests at different hydration temperatures (see figure 4-A), and this effect is more pronounced when the difference between hydration temperature and dehydration decreases.

\section{Conclusions}

In this work, the feasibility of two different materials was investigated for their utilization as $\mathrm{H}_{2} \mathrm{O}$ sorbents for the Sorption-Enhanced Methanation in an innovative configuration consisting of two interconnected fluidized beds. A calcium oxide, derived from an Italian natural limestone called Massicci, and a commercial $3 \mathrm{~A}$ zeolite were tested in a lab-scale dual fluidized bed apparatus, called Twin Beds, purposely designed for looping systems. The performance was evaluated in terms of the steam capture capacity and its release in multiple cycle tests of hydration and dehydration. The hydration steps were run in a reaction environment composed by $10 \%$ in volume of steam in air, while the dehydration steps in pure air. A sensitivity analysis was carried out at different temperatures of both hydration and dehydration to investigate the effect of these temperatures on both materials.

In general, $\mathrm{CaO}$ presents a decay of the steam capture capacity with the number of cycles in all conditions investigated. This decay is likely determined by the combination of chemical deactivation, induced by the irreversible carbonation of the sorbent with $\mathrm{CO}_{2}$ contained in the air, and the elutriation of fines particles due to attrition phenomena. The increase of the hydration temperature entails a negative effect during the first cycles, which tends to vanish with the increase of the cycle number. This behavior is probably due to the formation of a plugging external layer of $\mathrm{Ca}(\mathrm{OH})_{2}$ (and $\mathrm{CaCO}_{3}$ ) induced by faster reactions. Conversely, higher dehydration temperatures promote particle breakage with the formation of new surface with the consequent increase of the steam capture capacity.

On the other hand, the zeolite has a more stable behavior than $\mathrm{CaO}$ in all conditions investigated, and presents a slight activation during the first cycles. However, the hydration temperature has a similar effect as for $\mathrm{CaO}$, which determines a decrease of the steam capture capacity. The explanation of this trend is due to the less favorable physisorption with the increasing temperature.

Contrary to $\mathrm{CaO}$, the influence of the dehydration temperature on the zeolite seems to be strictly related to the hydration temperature. At low hydration temperature, a negative effect could be observed only at the highest dehydration temperature, probably induced by a modification of the structure of the zeolite. Instead, at higher hydration temperature the steam capture is principally limited by the thermodynamics of physisorption during the hydration stage.

Comparing the performance of the two materials, the zeolite on average has a better asymptotic capture capacity $(0.017$ $0.049 \mathrm{~g} / \mathrm{g})$ than $\mathrm{CaO}(0.006-0.025 \mathrm{~g} / \mathrm{g})$ and furthermore it is not affected by deactivation during the cycles. However, this is not the only parameter to be considered for the choice of the best sorbent for the sorption-enhanced methanation, because other features could be important, such as the different cost of the two sorbent, which is in favor of $\mathrm{CaO}$. In addition, another important factor is the attrition resistance of the sorbent in a fluidized bed environment, which will be the subject of future experimental tests. For steady operation in a dual fluidized bed reactor methanator (with continuous 
circulation of the sorbent to/from a regenerator reactor), the amount of water removed from the methanation reactor can be regulated by changing the sorbent circulation rate to/from the regenerator or by changing the ratio of sorbent to catalyst loading in the system. It is worth noting that a recent thermodynamic assessment showed that partial water capture might be preferable with respect to total water removal in order to avoid solid carbon formation (which would lead to catalyst deactivation) [26]. A detailed calculation of the optimal sorbent/catalyst ratio and solids circulation rate would need a preliminary definition of the best operating conditions in terms of the desired fractional amount of captured water.

\section{Acknowledgements}

N. Vallefuoco, C. De Giacomo, A. Esposito, A. Pace and L. Tregrossi are gratefully acknowledged for their help in performing the tests.

\section{References}

[1] A.H. Seifert et al., Appl. Energy 132 (2014) p155

[2] M. Götz et al., Renew. Energy 85 (2015) p1371

[3] S. Rönsch et al., Fuel 166 (2016) p276

[4] P. Sabatier et al., J. Chem. Soc. 82 (1902) p333

[5] G.P. Smestad et al., Ind. Eng. Chem. Res. 51 (2012) p11828

[6] R.M. Cuéllar-Franca et al., J. CO Utiliz. 9 (2015) p82

[7] G. Pleßmann et al., Energy Procedia 46 (2014) p22

[8] H.S.de Boer et al., Energy 72 (2014) p360

[9] J. Newton, in: 14TH ANNUAL APGTF WORKSHOP London, 2014 URL, http://www.apgtfuk.com/files/workshops/14thWorkshop2014

[10] J. Wallbrecht, Int. Gas Union Triennium 2003e2006-Working Committee 2: Underground Gas Storage, Amsterdam, 2006 URL, http://members.igu.org/html/wgc2006/WOC2database [11] P. Sabatier et al., Comptes Rendus Des Séances De L'Académie Des Sciences, Section VI - Chimie. Paris: Imprimerie Gauthier-Villars; 1902.

[12] W. Boll et al., In: Ullmann's encyclopedia of industrial chemistry. Weinheim: WileyVCH Verlag GmbH \& Co. KGaA; 2006. p. 85.

[13] S. Rönsch, Anlagenbilanzierung in der Energietechnik - Grundlagen, Gleichungen und Modelle für die Ingenieurpraxis. 1st ed. Wiesbaden: Springer Vieweg; 2015.

[14] G.A. Mills et al., Catal Rev 8 (1974) p159

[15] P. Panagiotopoulou et al., Appl Catal B 88 (2009) p470

[16] J.B. Powell et al., J Catal 94 (1985) p566

[17] InfoMine: http://www.infomine.com/investment/ruthenium/ [download: 04.06.2015].

[18] M.V. Twigg, Catalyst Handbook, second ed., Manson Publishing Ltd., London, 1996.

[19] C.H. Bartholomew, Appl Catal A 212 (2001) p17

[20] M. Seemann, PhD thesis. ETH Zurich; 2006.

[21] A. Borgschulte et al., Phys. Chem. Chem. Phys. 15 (2013) p9620

[22] S. Walspurger et al., Chem. Eng. J. 242 (2014) 379-386

[23] A. Coppola et al., Powder Technol. 316 (2017) p585

[24] A. Coppola et al., Energy \& Fuels 29 (2015) p4436

[25] F. Scala et al., AIChE J. 43 (1997) p363

[26] F. Massa et al., J. CO $\mathrm{CO}_{2}$ Utiliz. (2019) DOI: 10.1016/j.jcou.2019.09.014 